\section{Informing the public}
A
s described by Laura Eggertson and Barbara Sibbald, ${ }^{1}$ several Canadian health care institutions are struggling to contain an outbreak of Clostridium difficile infection. Because this disease is not reportable, it is up to individual institutions to determine how (and even whether) to disseminate information about the problem; how- ever, this ad hoc approach is woefully inadequate.
The public ought to have been made aware of the rise in rates of $C$. difficile infection when the increase first mani- fested itself. This would have allowed people to make informed decisions re- garding, say, elective hospital proce- dures that require use of antibiotics or proton pump inhibitors and to seek and receive prompt diagnosis and treatment if they experienced diarrhea. In making this information available, hospitals would have been abiding by the princi- ples of transparency and accountability on an issue that concerns the public, thus instilling trust in our health care institutions. Once the issue had been brought to light, institutions could have solicited government response and as- sistance on an issue that is essentially

social and, therefore, political.

Instead, public health officers are struggling with the problem and hospital staff are attempting to reduce the incidence of infection, but without a nationwide consensus on appropriate strategies.

There is a false belief that the public, if informed about the increased risk of contracting the infection, would become panic-stricken. Yet several studies have shown that the public demands comprehensive information about both the risks and the benefits of medical care, ${ }^{2,3}$ so that they can exercise their right to make informed decisions. ${ }^{4}$

Perhaps health care providers lack the time or resources to properly inform patients about the many risks of care in the hospital setting. But this raises the question of what sort of a health care system we really want one where an ethic of informed consent overrides expediency and lack of resources or the other way around?

\section{Joseph Erban}

Member, Clinical Ethics Committee

Jewish General Hospital

Montréal, Que.

\section{References}

1. Eggertson L, Sibbald B. Hospitals battling outbreaks of C. difficile. CMA7 2004;171(1):19-21.
2. Geller G, Strauss M, Bernhardt BA, Holtzman NA. "Decoding" informed consent. Insights from women regarding breast cancer susceptibity testing. Hastings Cent Rep 1997;27:28-33.

3. Gert HJ. Avoiding surprises. A model for informing patients. Hasting Cent Rep 2002;32(5): 23-32.

4. Munch S. Moral wounds: complicated complications. FAMA 2001;285:1131-2.

DOI:10.1503/cmaj.1041050

\section{Letter from the Himalayas}

T t was with great enthusiasm tem1 pered by sadness that I read Geoff Ibbotson's description of his experiences in $\mathrm{Nepal}^{1}$ as I prepared to head home to Nepal this year. The beginning of February is a good time to take a peek at the Himalayas, as the skies become clearer and the white snow melts on the mountains. But the colour characterizing the mountains this year was red. The whole country has been caught up in a cycle of violence since the beginning of the Maoist insurgency, which has claimed over 10000 lives and has now reached the capital city of Kathmandu.

We are all aware of the deplorable level of health care available in Nepal, but few, including me (a Nepalese native), are aware that the system can also offer good care at an affordable cost. 
Yet, as Ibbotson describes and as I experienced during my recent trip home, such affordable care is possible.

While in Nepal, I had the opportunity to visit some of the medical facilities in Kathmandu, and I was surprised at the speed and efficiency with which an elderly woman with congestive heart failure was managed at a governmentrun cardiac care hospital in Kathmandu. She had initially been treated for myocardial infarction at a regional hospital a few weeks before. On arrival at the cardiac hospital, the necessary investigations, including electrolyte measurement, radiography and echocardiography, were done and the patient was transferred to the intensive care unit. She was evaluated by a cardiologist and started on angiotensin-converting enzyme inhibitors, spironolactone and cardioselective $\beta$-blockers. She made an uneventful recovery the following week and was discharged to follow-up. The cost of her entire hospital stay? Less than US\$200!

Although my experience was limited to the city of Kathmandu, I am sure that the picture at many locations in the remote hills is not much different from what Ibbotson ${ }^{1}$ portrays.

Now, as I sit back in the comfort of my living room in the United States, I try to convince myself that the sun has not entirely set on "the roof of the world." A little help from the more fortunate ones and some reprieve from the cycle of fear and violence could go a long way toward improving the health care situation in Nepal.

\section{Sonal Singh}

Unity Health System

Rochester, NY

\section{Reference}

1. Ibbotson G. Nepal: a lesson from chaos. CMAJ 2003;169(12):1301-4.

DOI:10.1503/cmaj.1040496

\section{[The author responds:]}

S onal Singh's description of an el$S$ derly woman receiving excellent care at so little expense illustrates one of the wonderful things about living in
Kathmandu. The city is truly a different world from the remote valleys on the other side of the mountain ridge that surrounds the Kathmandu Valley. Yet while care is available at low cost in the city, there are many people outside Kathmandu who do not have the resources to cover even such relatively minor expenses: the average annual income is only US\$235. ${ }^{1}$ As the Maoist insurgency worsens and the economy crumbles, there is an ever-increasing need for charity health care to help the extremely poor. It is my hope that Nepali physicians, like Singh, will be enthusiastic about returning to their homeland to help build a better health care system, where even the poorest can find assistance. Such individuals represent the hope for the future of Nepal in this time of turmoil.

\section{Geoffrey C. Ibbotson}

Surgeon

Calgary, Alta.

\section{Reference}

1. Ibbotson G. Nepal: a lesson from chaos. CMA7 2003;169(12):1301-4.

DOI:10.1503/cmaj.1041012

\section{Test for defective afferent pupillary response}

\section{A} s an ophthalmologist, I have a question regarding the clinical history for the 16-year-old boy with progressive vision loss described by Shaun Morris and associates: ${ }^{1}$ Was the patient tested for a defective afferent pupillary response in the left eye? This is an important clinical sign of optic nerve function and in general is much more clinically significant than a colour vision test.

For patients presenting with unilateral loss of vision, the possible cause, be it retinal or related to the optic nerve, can be pinpointed by the results of the swinging flashlight test, also known as the Marcus-Gunn pupil test, which tests for defective afferent pupillary reflex.

The test consists of alternately illuminating the pupils with a penlight (or even the white light of an ophthalmoscope) in a dimly lit room, swinging the light from one eye to the other every 2 seconds or so. The observer checks for visible dilatation of the pupil in the eye with visual loss.

A positive result, in which the pupil exhibits visible dilatation, indicates optic nerve dysfunction or retinal "disconnection" (as in retinal detachment). A negative result, characterized by the maintenance of the initial pupillary constriction in both eyes equally, tends to indicate that the problem lies elsewhere, such as loss of vision associated with macular lesions, retinal vascular disease or cataracts.

\section{Alex Porzecanski}

Ophthalmologist

Victoria, BC

\section{Reference}

1. Morris S, Hiraki L, Muise A. A 16-year-old boy with progressive central vision loss in his left eye. CMAF 2004;170(8):1228

DOI:10.1503/cmaj.1040692

\section{[The authors respond:]}

$\mathrm{T}$ o respond to Alex Porzecanski's specific question, the patient that we described ${ }^{1}$ did indeed have a defective afferent pupillary response in the left eye, as would be expected with optic neuritis.

We can now provide an update on the patient's situation. He returned to the Hospital for Sick Children 4 months later with complete blindness in the left eye (the one with the defective afferent pupillary response). Repeat MRI showed multiple new lesions of the periventricular white matter. This MRI evidence of dissemination in time and space confirmed the diagnosis of multiple sclerosis.

\section{Aleixo Muise \\ Linda Hiraki \\ Shaun Morris \\ Department of Pediatrics \\ Hospital for Sick Children \\ Toronto, Ont. \\ Reference \\ 1. Morris S, Hiraki L, Muise A. A 16-year-old boy with progressive central vision loss in his left eye. CMAF 2004;170(8):1228.}

DOI:10.1503/cmaj.1040849 